\title{
From the NIH: Proceedings of a Workshop on the Importance of Self-Obtained Vaginal Specimens for Detection of Sexually Transmitted Infections
}

\author{
Marcia M. Hobbs, $\mathrm{PhD}^{\star}$, Barbara Van Der Pol, MPH, $\mathrm{PhD}^{\dagger}$, Patricia Totten, $\mathrm{PhD}^{\ddagger}$, Charlotte \\ A. Gaydos, DrPH ${ }^{\S}$, Anna Wald, MD, MPH ${ }^{\ddagger}$, Terri Warren, RN, ANP\|, Rachel L. Winer, PhD $^{\ddagger}$, \\ Robert L. Cook, MD, MPH", Carolyn D. Deal, PhD\#, M. Elizabeth Rogers, BS\#, Julius \\ Schachter, $\mathrm{PhD}^{\star \star}$, King K. Holmes, MD, $\mathrm{PhD}^{\ddagger}$, and David H. Martin, MD ${ }^{\dagger \dagger}$ \\ *University of North Carolina at Chapel Hill, Chapel Hill, North Carolina †'ndiana University, \\ Indianapolis, Indiana ‡University of Washington, Seattle, Washington §Johns Hopkins University, \\ Baltimore, Maryland "Westover Heights Clinic, Portland, Oregon IUniversity of Florida, \\ Gainesville, Florida \#National Institute of Allergy and Infectious Diseases, Bethesda, Maryland \\ * University of California, San Francisco, California ††Louisiana State University, New Orleans, \\ Louisiana
}

\begin{abstract}
On June 27, 2006, the NIH conducted a workshop to review published data and current field practices supporting the use of self-obtained vaginal swabs (SOVs) as specimens for diagnosis of sexually transmitted infections (STIs). The workshop also explored the design of studies that could support FDA clearance of SOVs for STI testing, particularly for specimens collected in nonclinical settings including patients' homes. This report summarizes the workshop findings and recommendations. Participants concluded that self-obtained vaginal swabs are well accepted by women of all ages and that SOVs perform as well as or better than other specimen types for Chlamydia trachomatis and Neisseria gonorrhoeae detection using transcription-mediated amplification. In addition, workshop participants recommended the validation of SOV testing by public health practitioners and manufacturers of STI diagnostic tests to expedite incorporation of SOVs as a diagnostic option in clinical and nonclinical settings for Chlamydia trachomatis and Neisseria gonorrhoeae testing. Similarly, SOVs should be explored for use in the diagnosis of other sexually transmitted pathogens.
\end{abstract}

At the beginning of the 21st century, we face stable or increasing infection rates for Chlamydia trachomatis (CT) and Neisseria gonorrhoeae (GC) in the United States. These are unacceptable circumstances in view of the serious negative impact of these infections on reproductive health and their relatively high prevalence in the United States compared with other industrialized countries. ${ }^{1,2}$ Clearly, reduction of prevalence and incidence requires improved intervention approaches, including better screening strategies.

$\mathrm{CT}$ and GC infections in the general population are often asymptomatic and consequently are underdiagnosed. ${ }^{3,4}$ Targeted screening programs in the United States have resulted in steady declines in the prevalence of these infections in the 1990s, a trend that unfortunately

Copyright (C) 2007, American Sexually Transmitted Diseases Association All rights reserved.

Correspondence: Marcia M. Hobbs, PhD, Department of Medicine, CB\# 7031, UNC School of Medicine, Chapel Hill, NC 27599. mmhobbs@med.unc.edu.

Other authors report no conflicts. 
has not been sustained in recent years. Surveillance statistics from the CDC reveal that reported cases of gonorrhea rose sharply from the mid 1960s through the 1970s, declined steadily until the mid 1990s and then plateaued. ${ }^{2}$ Comparable data for CT infections have been collected only since 1984, and nationwide, case rates appear to have risen steadily through the most recent annual data summary period in 2005 . However, screening for CT became widespread only after the advent of affordable, reliable detection methods including nucleic acid amplification tests (NAATs) in the 1990s, and case detection has been increasing steadily ever since. ${ }^{2}$ Thus, the apparent increase in CT case detection is likely due in part to increased case finding. However, in the northwestern states comprising Public Health Region X, funding for broad-based CT screening among women was initiated in 1988, and data have been collected on the number of tests performed and the percent of CT tests that were positive. In Region X, CT prevalence rates actually dropped steadily between 1988 and 1995 and then remained steady through 1997 (Fig. 1). ${ }^{5}$ Data from the regional Infertility Prevention Programs have provided good CT prevalence data from participating family planning clinics in the United States since the late 1990s. Infertility Prevention Programs data show that $\mathrm{CT}$ rates in women seen in these settings remained steady nationwide through 2005. ${ }^{5}$ Importantly, in Region X, where screening programs have been in place the longest, the percentage of women tested who have positive tests for CT is now rising, even after statistical adjustment for increases in test sensitivity (Fig. 1). The reasons for the lack of continued decline (and even increases) in both CT and GC prevalence are not entirely clear, but these trends may be consequences of initial screening programs that targeted only a subset of the population (those who attended the clinics), allowing continued spread in underserved sectors of the community (those who did not attend the clinics). Thus, it is logical to conclude that programs for screening all at-risk populations could further reduce sexually transmitted infection (STI) prevalence.

Possible strategies for reducing STI prevalence include expanding screening to nontraditional settings such as schools, juvenile detention centers, hospital emergency departments, and drug rehabilitation clinics. The availability of highly sensitive NAATs allows the use of specimens other than conventional clinician-obtained endocervical and urethral specimens, such as urine and vaginal specimens, for detection of CT and GC.

\section{Self-Obtained Vaginal Swab Specimens Perform Well for Detection of CT and GC Infections}

A major breakthrough in screening for $\mathrm{CT}$ and $\mathrm{GC}$ genital tract infections came with the recognition that by using highly sensitive NAATs, the organisms could be detected in urine from infected women. ${ }^{6}$ Shortly after this discovery, a number of investigators explored the use of vaginal swabs for detection of CT and GC by ligase chain reaction and transcriptionmediated amplification. ${ }^{7-9}$ These studies demonstrated that vaginal swabs are as sensitive as cervical swabs for the detection of $\mathrm{CT}$ and GC and more sensitive than urine specimens. Moreover, a multicenter study underscored the susceptibility of urine specimens to technical errors resulting from relatively demanding processing requirements, particularly the centrifugation step, which was unnecessary for vaginal swab specimens. ${ }^{10}$ In this study, the sensitivity of cervical swabs was about $90 \%$, whereas sensitivities for vaginal swabs were greater than $96 \%$ for each of the NAAT assays evaluated. In contrast, the combined sensitivity of urine-based assays in this study was only $81 \%$. Furthermore, self-obtained vaginal swabs (SOVs) performed as well as clinician-collected vaginal swabs. Some studies have shown vaginal swab specimens to be more sensitive than endocervical specimens, ${ }^{11,12}$ although the 2 specimen types showed equivalent performance in most studies. ${ }^{10,13,14}$ However, for detection of GC in women, not all NAATs exhibit acceptable performance with specimens other than endocervical swabs. Of particular note, neither urine nor SOVs showed adequate sensitivity for detection of GC with the Roche Amplicor PCR assay. ${ }^{15}$ It 
has been clearly demonstrated that the vaginal swab is an acceptable and accurate specimen type, and use of swab specimens is more sensitive than use of first-catch urine specimens for detection of CT and GC using transcription-mediated amplification.

\section{Self-Collection of Vaginal Specimens Is Acceptable to Women}

Women prefer vaginal swab self-collection over pelvic examination in most settings, and SOV collection is at least as well accepted as, and often preferred to the collection of firstcatch urines. ${ }^{14}$ In a longitudinal study of adolescent women, participants were willing to collect weekly vaginal swabs for STI testing during 12-week periods for up to 6 years. ${ }^{16}$ In a recent study in which subjects were recruited via the Internet, over 500 women in the Baltimore area submitted SOVs for CT and GC testing. ${ }^{17}$ Women of all ages have proven willing and capable of SOV collection in a variety of nonclinic settings including homes, ${ }^{16}$ high schools, ${ }^{18}$ military bases, ${ }^{19-21}$ correctional facilities, ${ }^{22,23}$ university health centers, ${ }^{24}$ substance abuse treatment facilities, ${ }^{25-27}$ and geographically remote communities. ${ }^{28-33}$ Selfsampling enables STI testing in settings where considerable barriers prevent conventional specimen collection.

\section{Innovative CT and GC Screening Strategies Are Possible With Self- Obtained Vaginal Specimens}

Currently, the FDA has cleared only 1 CT/GC NAAT (Gen-Probe's APTIMA Combo2 assay) for use with SOVs, and clearance is limited to self or clinician collection of specimens in the clinic. This restriction clearly hinders more widespread use of vaginal swabs and largely negates the advantages offered by self-collection. Therefore, validation for the use of SOVs in nonclinic settings is urgently needed.

Preliminary studies demonstrated the feasibility of home-based specimen collection for CT testing. In a Danish study, participants were mailed specimen self collection kits or an informational packet containing a card that could be mailed in to obtain a kit. ${ }^{34,35}$ Program approval was high, and women with access to home specimen collection were 3 to 4 times more likely to be tested than women who had to visit a physician for testing during usual care. In the United States, women who were screened using home-collected SOVs received significantly more tests for gonorrhea and chlamydial infection, compared with women who received invitations to come into a clinic for testing. ${ }^{36}$ In a small study in Seattle, patients with CT or GC infections were contacted posttreatment and invited to participate in a study for rescreening. ${ }^{37}$ Among participants given the option to return to the clinic for testing or collect a specimen at home and mail it to the clinic, $70 \%$ opted for self collection, and $60 \%$ of subjects were rescreened. The results of these studies demonstrate the acceptability and success of CT and/or GC screening using specimens collected at home and mailed into the laboratory. Screening with home-based specimen collection is likely to be more costeffective than clinic-based testing because costs of clinic visits and pelvic examinations would be eliminated. ${ }^{38}$

\section{SOVs Expand Our Ability to Study the Epidemiology of STIs in the Field}

A fundamental limitation in collection of population-based epidemiologic data is the requirement that individuals be tested in a clinical setting. Over the last decade, the use of urine samples has expanded access to field-based settings. However, problems with urine transport and nucleic acid target instability in urine continue to hamper the study of nonclinic-based populations. SOVs have the potential to circumvent many of these problems. 
In a population-based study of adolescent sexual behaviors and risk factors, SOVs were used for STI diagnostics and experimental detection assays. ${ }^{16,39-42}$ Prevalence estimates in this population were established for CT and GC and several other STIs. In addition, this study followed the natural histories of Trichomonas vaginalis (TV), Mycoplasma genitalium (MG), and sexually transmitted viral infections in young women. In some cases, a single SOV was used for detection of DNA from CT, GC, TV, MG, herpes simplex virus (HSV), and human papillomavirus (HPV). The experience from this study suggests that this method could be used for population-based screening efforts for numerous sexually transmitted organisms once appropriate specimen transport and processing conditions are defined.

\section{SOVs Are Optimal Specimens for Detection of $T$. vaginalis and $M$. genitalium Infections}

The emphasis on the use of self-obtained specimens for detection of CT and GC reflects predominant focus in the current literature on studies regarding the use of SOVs for detection of these infections and the current availability of FDA-cleared tests for diagnosis of gonorrhea and chlamydial infections. However, the workshop also reviewed the growing literature on the performance of SOVs for detecting other reproductive tract infections including TV, MG, HSV, HPV, and bacterial vaginosis.

Compared with tests for CT and GC, development of NAATs for other sexually transmitted infections has received less attention from the diagnostics industry. However, analytespecific reagents for detection of TV are commercially available for use with the Gen-Probe transcription-mediated amplification (TMA) platform, and a TMA research assay for MG is in development. In addition, numerous in-house NAATs have been used to detect these organisms, and published reports suggest that SOVs may be the best specimen for detection of these 2 increasingly important pathogens.

Unlike $\mathrm{CT}$ and GC, which primarily infect the cervix and are shed into the vagina, the protozoan parasite TV primarily infects the vagina. Thus, vaginal swabs are ideal specimens for the detection of this widespread, but underdiagnosed sexually transmitted pathogen. Provider-collected vaginal swabs have long been used to test for trichomoniasis in STD clinic settings using wet mount microscopy and culture. For detection of TV using culture ${ }^{43}$ or PCR, ${ }^{12,21,44}$ test performance is equivalent for SOVs and provider-collected vaginal swabs. SOVs also perform well with the Gen-Probe TV analyte-specific reagents. ${ }^{45}$ Furthermore, SOVs have proven superior to urine as specimens for TV PCR. ${ }^{44,46}$

MG is a newly recognized pathogen associated with reproductive tract infections in both men and women. In a study of MG infection in women attending a northwestern US STD clinic, Totten and colleagues compared genital specimen types for MG detection using the Gen-Probe TMA research assay and in-house PCR assays. ${ }^{47}$ In this study, vaginal swabs were superior to cervical swabs and urine specimens in both NAATs for detection of MG. Thus, in addition to their utility for CT, GC testing, SOVs should facilitate screening programs for TV and MG.

\section{SOV Used for Detection of HSV, HPV, and Organisms Associated With BV}

Self-obtained genital samples including SOVs have played a pivotal role in defining the natural history of genital herpes and have increasingly been used to evaluate the efficacy of therapeutics and candidate therapeutic vaccinations. ${ }^{48-51}$ Because HSV is present on the mucosa intermittently, one-time cross-sectional population sampling of genital secretions for the virus will identify only a small proportion of those infected. However, daily selfobtained swabs of genital mucosa over prolonged intervals in both women and men have 
shown that almost all persons with HSV-2 experience viral reactivation and most have recurrent genital lesions. ${ }^{52}$

Unlike the STIs discussed above for which vaginal specimens are appropriate for screening, SOVs for HPV testing appear less likely to replace cervical specimens for detecting highgrade cervical lesions and invasive cervical cancer in most clinical settings. As a diagnostic tool for detecting high-grade cervical lesions and invasive cervical cancer, SOVs have been reported to be equally or less sensitive than clinician-collected direct cervical sampling, and less specific. ${ }^{53-63}$ Nevertheless, SOVs for HPV testing have potential applications for both clinical practice and research. SOVs may be useful in situations where clinician-performed sampling is not feasible, and could be effective in increasing screening coverage or adherence to recommendations for follow-up of equivocal Pap results. As a research tool, SOVs could allow increased participation in and feasibility of large-scale phase intravenous vaccine studies designed to investigate HPV transmission dynamics and the population-level impact of vaccines on HPV prevalence. Initial studies of self-obtained vaginal specimens for HPV detection are encouraging; several studies reported higher rates of HPV detection in SOVs than in clinician-collected cervical samples in clinic settings. ${ }^{58,64}$ In a recent report published after the workshop, Dunne and colleagues from the CDC describe high HPV prevalence detected in SOVs collected at home by women in the 2003 to 2004 US National Health and Nutrition Examination Survey. ${ }^{65}$ Additional studies are needed to determine the utility of self-collected vaginal swabs for HPV detection in other nonclinical settings.

In contrast to the genital tract infections caused by individual microbes, bacterial vaginosis is characterized by the replacement of the normal predominant Lactobacillus vaginal flora with a mixed flora including Gardnerella vaginalis, anaerobes, and other bacteria. Diagnosis of $\mathrm{BV}$ is generally based either on physical examination or on the assessment of vaginal bacterial morphotypes by Gram stain. ${ }^{66}$ SOVs have been used successfully for home-based collection and clinic-based research studies for BV testing by Gram stain and are acceptable to women ${ }^{67-70} \mathrm{~A}$ role for SOVs in routine clinical practice and home collection is promising but currently untested.

\section{What Is the Way Forward?}

Abundant evidence supports the use of SOVs for STI testing, most clearly at this time for detection of CT and GC using transcription-mediated amplification, since the LCR assay is no longer available. Although no single specimen type will detect all chlamydial or gonococcal infections, there is ample proof that vaginal swabs perform at least as well as other specimen types by TMA, and they are clearly superior to the main alternative noninvasive specimen-first-catch urine. In addition, the simpler processing requirements for vaginal swabs than for urine make them less susceptible to laboratory error with NAATs that do not include a target capture step. Women are adept at self-collection, and in settings where pelvic examinations and traditional specimen collection and testing are not available, SOVs offer an opportunity to increase screening and thereby hopefully further reduce CT and GC infections in women. SOVs are the specimen of choice for women in programs for self-motivated chlamydia and gonorrhea screening. It remains to be seen how widely acceptable such programs will be for the detection of CT and GC infections among sexually active, asymptomatic women in the general population. The FDA has cleared the use of kits for self-motivated, self-collection of specimens for HIV and Hepatitis C testing, and such kits are available via the Internet and in pharmacies. We anticipate that home-collected and mailed SOVs will be important in increasing the detection and treatment of chlamydia and gonorrhea as well as other STIs in women. 
To achieve the maximum immediate benefit, SOVs should be compatible with multiple CT/

GC NAAT platforms. Currently, each test requires a specific transport and storage buffer for provider-collected cervical or vaginal swabs. In a small preliminary study, the sensitivity of a commercial PCR test for detection of CT and GC in dry vaginal swabs (transported in containers with no added liquid) was not statistically different than for swabs that were placed in specimen transport buffer immediately after collection. ${ }^{20} \mathrm{We}$ recommend the development and assessment of a specimen collection kit for mailing dry SOVs to the laboratory, compatible with all NAAT platforms eventually approved for SOV testing, with standard reconstitution instructions for optimal performance of this specimen type. In addition, specimen validation under conditions likely to be encountered during transport by mail is needed for commercially available NAATs.

From the public health perspective, there are many reasons to encourage more widespread use of SOVs for the detection of CT, GC and other STI pathogens. STI testing using selfobtained specimens will not replace clinic-based speculum examination and counseling by clinicians. However, self-collection programs should enhance participation in targeted screening programs - for example, for posttreatment detection of recurrent chlamydial infections in women. Moreover, women should have the opportunity to protect themselves from the consequences of CT and CG infection through self-motivated specimen selfcollection in their homes if they feel they may be at risk for infection. Validation of SOVs for this purpose is needed to permit the implementation of such testing as well as the development of innovative approaches to self-sampling in a wide variety of circumstances. SOVs may enhance testing for women who refuse an examination, for women in late pregnancy, or for young women who may not yet need a Papanicolaou smear examination and may be discouraged from attending the clinic by the prospect of a speculum examination, yet are at risk of acquiring an STI. ${ }^{15}$ Early data have shown SOVs and other self-collected specimens to be effective research tools for TV and MG as well as for sexually transmitted viruses. SOVs have proven very useful in longitudinal studies of the natural history of recurrent genital herpes virus infection, and this model could be applied to studies of the epidemiology and natural history of other STIs as well.

We encourage the STI research community and the public health community to work together with the diagnostics industry to develop validation protocols for SOVs to obtain the evidence needed for FDA clearance for their routine use in the diagnosis of CT and GC infections now, and for other STI pathogens in the near future. The self-obtained vaginal swab has the potential for use as a "universal" specimen for detection of lower genital tract infections in women, and will allow the assessment of these infections in an increasingly wide variety of settings.

\section{Acknowledgments}

Supported by the NIH Sexually Transmitted Infections and Topical Microbicides Cooperative Research Center grants U19-AI031448, U19-AI031494, U19-AI031496, U19-AI045429, U19-AI061972, and U19-AI062150.

Dr. Hobbs reports receiving research support from Gen-Probe, Inc. Dr. Van Der Pol reports receiving honoraria for talks presented and research support from Abbott Laboratories, BD Diagnostics, Gen-Probe, Inc., Roche Molecular Diagnostics and Digene Corp. Dr. Totten reports receiving honoraria for talks presented and research support from Gen-Probe, Inc. Dr. Gaydos reports receiving honoraria for talks presented and research support from BD Diagnostics and Gen-Probe, Inc. Dr. Wald reports receiving research support from GlaxoSmithKline, Antigenics, Inc., 3M, Roche, Vical, and Astellas. She is a consultant for Novartis, PowderMed, and Medigene and is a speaker for Merck Vaccines. Ms. Warren reports receiving honoraria for talks presented and research support from GlaxoSmithKline, Novartis, and Merck. Dr. Martin reports receiving research support from Gen-Probe, Inc. 


\section{References}

1. Eng, TR.; Butler, WT., editors. Committee on Prevention and Control of Sexually Transmitted Disease. The Hidden Epidemic: Confronting Sexually Transmitted Disease Institute of Medicine Report. Washington, DC: National Academy Press; 1997.

2. Centers for Disease Control and Prevention. Sexually Transmitted Disease Surveillance 2005. Health and Human Services; 2005.

3. Miller WC, Ford CA, Morris M, et al. Prevalence of chlamydial and gonococcal infections among young adults in the United States. JAMA. 2004; 291:2229-2236. [PubMed: 15138245]

4. Turner CF, Rogers SM, Miller HG, et al. Untreated gonococcal and chlamydial infection in a probability sample of adults. JAMA. 2002; 287:726-733. [PubMed: 11851539]

5. Centers for Disease Control and Prevention. Sexually Transmitted Disease Surveillance 2005 Supplement, Chlamydia Prevalence Monitoring Project Annual Report 2005. Health and Human Services; 2005.

6. Lee HH, Chernesky MA, Schachter J, et al. Diagnosis of Chlamydia trachomatis genitourinary infection in women by ligase chain reaction assay of urine. Lancet. 1995; 345:213-216. [PubMed: 7823713]

7. Hook EW III, Ching SF, Stephens J, et al. Diagnosis of Neisseria gonorrhoeae infections in women by using the ligase chain reaction on patient-obtained vaginal swabs. J Clin Microbiol. 1997; 35:2129-2132. [PubMed: 9230396]

8. Hook EW III, Smith K, Mullen C, et al. Diagnosis of genitourinary Chlamydia trachomatis infections by using the ligase chain reaction on patient-obtained vaginal swabs. J Clin Microbiol. 1997; 35:2133-2135. [PubMed: 9230397]

9. Stary A, Schuh E, Kerschbaumer M, et al. Performance of transcription-mediated amplification and ligase chain reaction assays for detection of chlamydial infection in urogenital samples obtained by invasive and noninvasive methods. J Clin Microbiol. 1998; 36:2666-2670. [PubMed: 9705411]

10. Schachter J, McCormack WM, Chernesky MA, et al. Vaginal swabs are appropriate specimens for diagnosis of genital tract infection with Chlamydia trachomatis. J Clin Microbiol. 2003; 41:37843789. [PubMed: 12904390]

11. Shafer MA, Moncada J, Boyer CB, et al. Comparing first-void urine specimens, self-collected vaginal swabs, and endocervical specimens to detect Chlamydia trachomatis and Neisseria gonorrhoeae by a nucleic acid amplification test. J Clin Microbiol. 2003; 41:4395-4399. [PubMed: 12958275]

12. Garrow SC, Smith DW, Harnett GB. The diagnosis of chlamydia, gonorrhoea, and trichomonas infections by self obtained low vaginal swabs, in remote northern Australian clinical practice. Sex Transm Infect. 2002; 78:278-281. [PubMed: 12181467]

13. Schachter J, Chernesky MA, Willis DE, et al. Vaginal swabs are the specimens of choice when screening for Chlamydia trachomatis and Neisseria gonorrhoeae: Results from a multicenter evaluation of the APTIMA assays for both infections. Sex Transm Dis. 2005; 32:725-728. [PubMed: 16314767]

14. Chernesky MA, Hook EW III, Martin DH, et al. Women find it easy and prefer to collect their own vaginal swabs to diagnose Chlamydia trachomatis or Neisseria gonorrhoeae infections. Sex Transm Dis. 2005; 32:729-733. [PubMed: 16314768]

15. Knox J, Tabrizi SN, Miller P, et al. Evaluation of self-collected samples in contrast to practitioner collected samples for detection of Chlamydia trachomatis, Neisseria gonorrhoeae, and Trichomonas vaginalis by polymerase chain reaction among women living in remote areas. Sex Transm Dis. 2002; 29:647-654. [PubMed: 12438900]

16. Van Der Pol B, Williams JA, Orr DP, et al. Prevalence, incidence, natural history, and response to treatment of Trichomonas vaginalis infection among adolescent women. J Infect Dis. 2005; 192:2039-2044. [PubMed: 16288365]

17. Gaydos CA, Dwyer K, Barnes M, et al. Internet-based screening for Chlamydia trachomatis to reach non-clinic populations with mailed self-administered vaginal swabs. Sex Transm Dis. 2006; 33:451-457. [PubMed: 16652069] 
18. Wiesenfeld HC, Heine RP, Rideout A, et al. The vaginal introitus: A novel site for Chlamydia trachomatis testing in women. Am J Obstet Gynecol. 1996; 174:1542-1546. [PubMed: 9065126]

19. Hsieh YH, Howell MR, Gaydos JC, et al. Preference among female Army recruits for use of selfadministrated vaginal swabs or urine to screen for Chlamydia trachomatis genital infections. Sex Transm Dis. 2003; 30:769-773. [PubMed: 14520176]

20. Gaydos CA, Crotchfelt KA, Shah N, et al. Evaluation of dry and wet transported intravaginal swabs in detection of Chlamydia trachomatis and Neisseria gonorrhoeae infections in female soldiers by PCR. J Clin Microbiol. 2002; 40:758-761. [PubMed: 11880389]

21. Rompalo AM, Gaydos CA, Shah N, et al. Evaluation of use of a single intravaginal swab to detect multiple sexually transmitted infections in active-duty military women. Clin Infect Dis. 2001; 33:1455-1461. [PubMed: 11568849]

22. Holland-Hall CM, Wiesenfeld HC, Murray PJ. Self-collected vaginal swabs for the detection of multiple sexually transmitted infections in adolescent girls. J Pediatr Adolesc Gynecol. 2002; 15:307-313. [PubMed: 12547662]

23. Newman SB, Nelson MB, Gaydos CA, et al. Female prisoners' preferences of collection methods for testing for Chlamydia trachomatis and Neisseria gonorrhoeae infection. Sex Transm Dis. 2003; 30:306-309. [PubMed: 12671549]

24. Serlin M, Shafer MA, Tebb K, et al. What sexually transmitted disease screening method does the adolescent prefer? Adolescents' attitudes toward first-void urine, self-collected vaginal swab, and pelvic examination. Arch Pediatr Adolesc Med. 2002; 156:588-591. [PubMed: 12038892]

25. Bachmann LH, Desmond RA, Stephens J, et al. Duration of persistence of gonococcal DNA detected by ligase chain reaction in men and women following recommended therapy for uncomplicated gonorrhea. J Clin Microbiol. 2002; 40:3596-3601. [PubMed: 12354851]

26. Bradshaw CS, Pierce LI, Tabrizi SN, et al. Screening injecting drug users for sexually transmitted infections and blood borne viruses using street outreach and self collected sampling. Sex Transm Infect. 2005; 81:53-58. [PubMed: 15681724]

27. Lally MA, Alvarez S, Macnevin R, et al. Acceptability of sexually transmitted infection screening among women in short-term substance abuse treatment. Sex Transm Dis. 2002; 29:752-755. [PubMed: 12466715]

28. Gare J, Lupiwa T, Suarkia DL, et al. High prevalence of sexually transmitted infections among female sex workers in the Eastern Highlands Province of Papua New Guinea: Correlates and recommendations. Sex Transm Dis. 2005; 32:466-473. [PubMed: 16041247]

29. Mgone CS, Passey ME, Anang J, et al. Human immunodeficiency virus and other sexually transmitted infections among female sex workers in two major cities in Papua New Guinea. Sex Transm Dis. 2002; 29:265-270. [PubMed: 11984442]

30. Tabrizi SN, Paterson B, Fairley CK, et al. A self-administered technique for the detection of sexually transmitted diseases in remote communities. J Infect Dis. 1997; 176:289-292. [PubMed: 9207385]

31. Tabrizi SN, Paterson BA, Fairley CK, et al. Comparison of tampon and urine as self-administered methods of specimen collection in the detection of Chlamydia trachomatis, Neisseria gonorrhoeae and Trichomonas vaginalis in women. Int J STD AIDS. 1998; 9:347-349. [PubMed: 9671249]

32. White PJ, Carcamo C, Garnett GP, et al. Patterns of sexually-transmitted infection prevalence as markers of HIV risk: Surveys of sexual behaviour and infection prevalences of the general population, sex workers and their clients in 24 cities throughout Peru. Int Conf AIDS. 2004; 15 abstract no. ThPeC7347.

33. Kim AA, Sun LP, Chhorvann C, et al. High prevalence of HIV and sexually transmitted infections among indirect sex workers in Cambodia. Sex Transm Dis. 2005; 32:745-751. [PubMed: $16314771]$

34. Andersen B, Gundgaard J, Kretzschmar M, et al. Prediction of costs, effectiveness, and disease control of a population-based program using home sampling for diagnosis of urogenital Chlamydia trachomatis infections. Sex Transm Dis. 2006; 33:407-415. [PubMed: 16601656]

35. Andersen B, Ostergaard L, Moller JK, et al. Effectiveness of a mass media campaign to recruit young adults for testing of Chlamydia trachomatis by use of home obtained and mailed samples. Sex Transm Infect. 2001; 77:416-418. [PubMed: 11714938] 
36. Cook RL, Ostergaard L, Hillier SL, et al. Home screening for sexually transmitted diseases in high-risk young women: Randomized controlled trial. Sex Transm Infect. 2007; 83:286-291. [PubMed: 17301105]

37. Sparks R, Helmers JR, Handsfield HH, et al. Rescreening for gonorrhea and chlamydial infection through the mail: A randomized trial. Sex Transm Dis. 2004; 31:113-116. [PubMed: 14743074]

38. Shafer MA, Pantell RH, Schachter J. Is the routine pelvic examination needed with the advent of urine-based screening for sexually transmitted diseases? Arch Pediatr Adolesc Med. 1999; 153:119-125. [PubMed: 9988241]

39. Brown DR, Shew ML, Qadadri B, et al. A longitudinal study of genital human papillomavirus infection in a cohort of closely followed adolescent women. J Infect Dis. 2005; 191:182-192. [PubMed: 15609227]

40. Fife KH, Fortenberry JD, Ofner S, et al. Incidence and prevalence of herpes simplex virus infections in adolescent women. Sex Transm Dis. 2006; 33:441-444. [PubMed: 16540882]

41. Shew ML, Fortenberry JD, Tu W, et al. Association of condom use, sexual behaviors, and sexually transmitted infections with the duration of genital human papillomavirus infection among adolescent women. Arch Pediatr Adolesc Med. 2006; 160:151-156. [PubMed: 16461870]

42. Tosh AK, Van Der Pol B, Fortenberry JD, et al. Mycoplasma genitalium among adolescent women and their partners. J Adolesc Health. 2007; 40:412-417. [PubMed: 17448398]

43. Schwebke JR, Morgan SC, Pinson GB. Validity of self-obtained vaginal specimens for diagnosis of trichomoniasis. J Clin Microbiol. 1997; 35:1618-1619. [PubMed: 9163499]

44. Smith KS, Tabrizi SN, Fethers KA, et al. Comparison of conventional testing to polymerase chain reaction in detection of Trichomonas vaginalis in indigenous women living in remote areas. Int $\mathrm{J}$ STD AIDS. 2005; 16:811-815. [PubMed: 16336764]

45. Hardick A, Hardick J, Wood BJ, et al. Comparison between the Gen-Probe transcription-mediated amplification Trichomonas vaginalis research assay and real-time PCR for Trichomonas vaginalis detection using a Roche LightCycler instrument with female self-obtained vaginal swab samples and male urine samples. J Clin Microbiol. 2006; 44:4197-4199. [PubMed: 16943353]

46. Van Der Pol B, Kraft CS, Williams JA. Use of an adaptation of a commercially available PCR assay aimed at diagnosis of chlamydia and gonorrhea to detect Trichomonas vaginalis in urogenital specimens. J Clin Microbiol. 2006; 44:366-373. [PubMed: 16455885]

47. Wroblewski JK, Manhart LE, Dickey KA, et al. Comparison of transcription-mediated amplification and PCR assay results for various genital specimen types for detection of Mycoplasma genitalium. J Clin Microbiol. 2006; 44:3306-3312. [PubMed: 16954265]

48. Straus SE, Seidlin M, Takiff HE, et al. Effect of oral acyclovir treatment on symptomatic and asymptomatic virus shedding in recurrent genital herpes. Sex Transm Dis. 1989; 16:107-113 [PubMed: 2545002]

49. Wald A, Corey L, Cone R, et al. Frequent genital herpes simplex virus 2 shedding in immunocompetent women. Effect of acyclovir treatment. J Clin Invest. 1997; 99:1092-1097. [PubMed: 9062368]

50. Brock BV, Selke S, Benedetti J, et al. Frequency of asymptomatic shedding of herpes simplex virus in women with genital herpes. JAMA. 1990; 263:418-420. [PubMed: 2152951]

51. Diaz-Mitoma F, Ruben M, Sacks S, et al. Detection of viral DNA to evaluate outcome of antiviral treatment of patients with recurrent genital herpes. J Clin Microbiol. 1996; 34:657-663. [PubMed: 8904433]

52. Wald A, Zeh J, Selke S, et al. Reactivation of genital herpes simplex virus type 2 infection in asymptomatic seropositive persons. N Engl J Med. 2000; 342:844-850. [PubMed: 10727588]

53. Sellors JW, Lorincz AT, Mahony JB, et al. Comparison of self-collected vaginal, vulvar and urine samples with physician-collected cervical samples for human papillomavirus testing to detect high-grade squamous intraepithelial lesions. CMAJ. 2000; 163:513-518. [PubMed: 11006761]

54. Wright TC Jr, Denny L, Kuhn L, et al. HPV DNA testing of self-collected vaginal samples compared with cytologic screening to detect cervical cancer. JAMA. 2000; 283:81-86. [PubMed: 10632284]

55. Belinson JL, Qiao YL, Pretorius RG, et al. Shanxi Province cervical cancer screening study II: Self-sampling for high-risk human papillomavirus compared to direct sampling for human 
papillomavirus and liquid based cervical cytology. Int J Gynecol Cancer. 2003; 13:819-826. [PubMed: 14675319]

56. Dannecker C, Siebert U, Thaler CJ, et al. Primary cervical cancer screening by self-sampling of human papillomavirus DNA in internal medicine outpatient clinics. Ann Oncol. 2004; 15:863869. [PubMed: 15151941]

57. Seo SS, Song YS, Kim JW, et al. Good correlation of HPV DNA test between self-collected vaginal and clinician-collected cervical samples by the oligonucleotide microarray. Gynecol Oncol. 2006; 102:67-73. [PubMed: 16375952]

58. Winer RL, Feng Q, Hughes JP, et al. Concordance of self-collected and clinician-collected swab samples for detecting human papillomavirus DNA in women 18 to 32 years of age. Sex Transm Dis. 2006

59. Garcia F, Barker B, Santos C, et al. Cross-sectional study of patient- and physician-collected cervical cytology and human papillomavirus. Obstet Gynecol. 2003; 102:266-272. [PubMed: 12907098]

60. Harper DM, Noll WW, Belloni DR, et al. Randomized clinical trial of PCR-determined human papillomavirus detection methods: Self-sampling versus clinician-directed-biologic concordance and women's preferences. Am J Obstet Gynecol. 2002; 186:365-373. [PubMed: 11904593]

61. Hillemanns P, Kimmig R, Huttemann U, et al. Screening for cervical neoplasia by self-assessment for human papillomavirus DNA. Lancet. 1999; 354:1970. [PubMed: 10622304]

62. Kahn JA, Slap GB, Huang B, et al. Comparison of adolescent and young adult self-collected and clinician-collected samples for human papillomavirus. Obstet Gynecol. 2004; 103:952-959. [PubMed: 15121570]

63. Lorenzato FR, Singer A, Ho L, et al. Human papillomavirus detection for cervical cancer prevention with polymerase chain reaction in self-collected samples. Am J Obstet Gynecol. 2002; 186:962-968. [PubMed: 12015522]

64. Gravitt PE, Lacey JV Jr, Brinton LA, et al. Evaluation of self-collected cervicovaginal cell samples for human papillomavirus testing by polymerase chain reaction. Cancer Epidemiol Biomarkers Prev. 2001; 10:95-100. [PubMed: 11219778]

65. Dunne EF, Unger ER, Sternberg M, et al. Prevalence of HPV infection among females in the United States. JAMA. 2007; 297:813-819. [PubMed: 17327523]

66. Nugent RP, Krohn MA, Hillier SL. Reliability of diagnosing bacterial vaginosis is improved by a standardized method of gram stain interpretation. J Clin Microbiol. 1991; 29:297-301. [PubMed: 1706728]

67. Boskey ER, Atherly-Trim SA, O'Campo PJ, et al. Acceptability of a self-sampling technique to collect vaginal smears for gram stain diagnosis of bacterial vaginosis. Womens Health Issues. 2004; 14:14-18. [PubMed: 15001184]

68. Yen S, Shafer MA, Moncada J, et al. Bacterial vaginosis in sexually experienced and non-sexually experienced young women entering the military. Obstet Gynecol. 2003; 102:927-933. [PubMed: 14672465]

69. Bradshaw CS, Morton AN, Hocking J, et al. High recurrence rates of bacterial vaginosis over the course of 12 months after oral metronidazole therapy and factors associated with recurrence. $\mathrm{J}$ Infect Dis. 2006; 193:1478-1486. [PubMed: 16652274]

70. Strauss RA, Eucker B, Savitz DA, et al. Diagnosis of bacterial vaginosis from self-obtained vaginal swabs. Infect Dis Obstet Gynecol. 2005; 13:31-35. [PubMed: 16040325] 


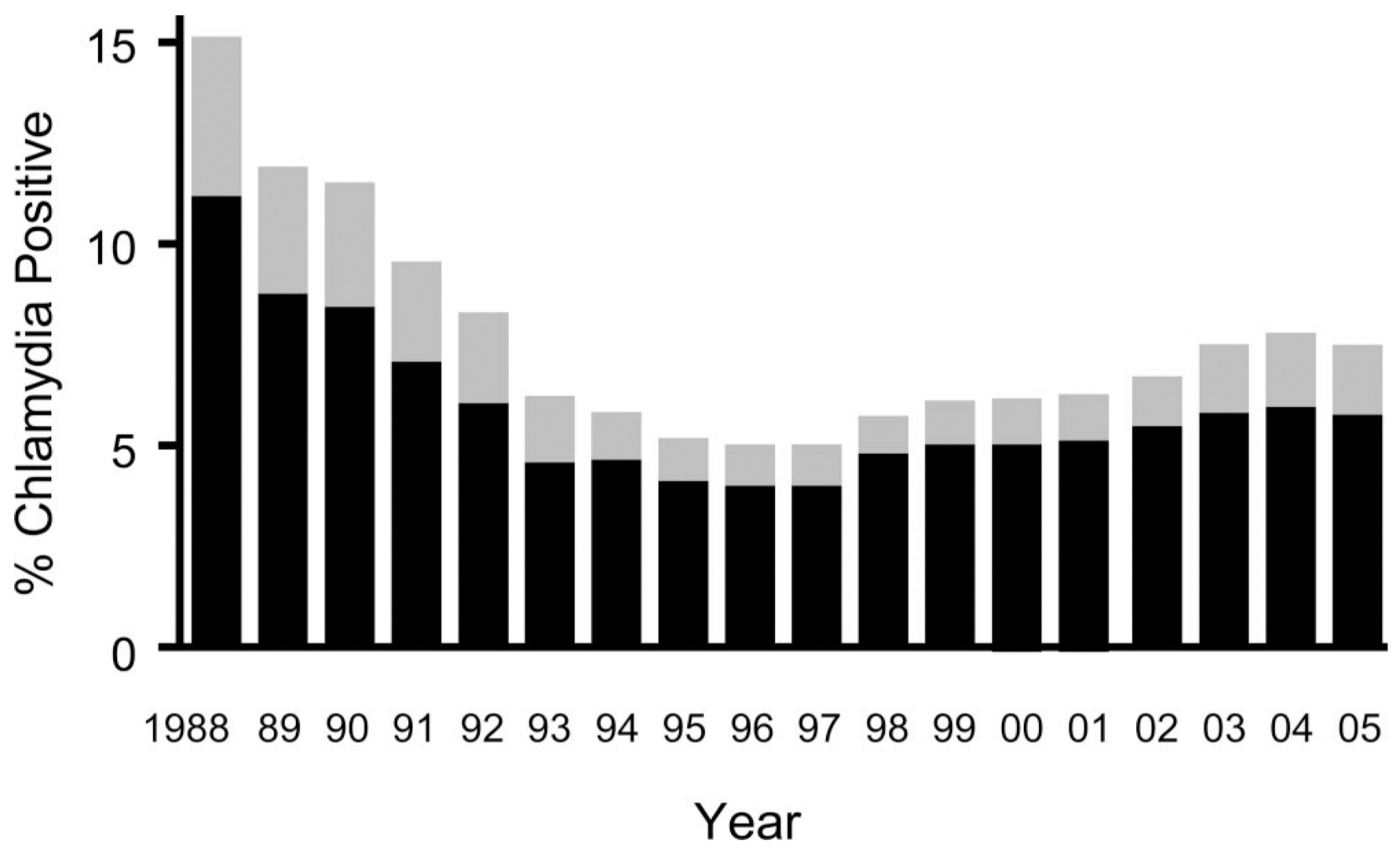

Fig. 1.

Trends in Chlamydia trachomatis positivity among 15- to 24-year old women tested in family planning clinics in northwestern states of Public Health Region X, 1988 to 2005. Data are from the Centers for Disease Control and Prevention. ${ }^{5}$ Black bars are unadjusted, and gray bars are adjusted for changes in laboratory test methods and associated increases in test sensitivity. 
Conclusions and Recommendations from the NIH Workshop on the Importance of Self-Obtained Vaginal Specimens for Detection of Sexually Transmitted Infections

- Self-obtained vaginal swabs (SOVs) are well-accepted by women, and these specimens perform better than urine for the diagnosis of CT and GC infections using nucleic acid amplification tests.

- More widespread use of SOVs for the detection of CT and GC offers potential benefit for public health. Women who feel they are at risk for CT or GC infection should have the opportunity for testing using self-motivated, self-collection in their homes.

- SOVs and other self-collected specimens are promising clinical and research tools for detection of sexually transmitted viruses as well as for Trichomonas vaginalis, Mycoplasma genitalium and bacterial vaginosis.

- The public health and STI research communities must work with the diagnostics industry to obtain FDA clearance for the routine use of SOVs in the diagnosis of CT and GC infections.

- Independent validation of SOVs by diagnostic laboratories is needed to facilitate innovative approaches including selfsampling in a wide variety of circumstances.

Fig. 2. 